木本性渓流沿い植物と幼期溪流沿い植物

\title{
邑田 仁：東京大学理学部附属植物園
}

Shrubby rheophytes and paedorheophytes

Jin Murata, Botanical Gardens, Faculty of Science, University of Tokyo, 3-7-1 Hakusan, Tokyo 112

\section{Abstract}

Shrubby rheophytes are characterized by sympodial branching as well as the general characters of rheophytes. Paedorheophytes are woody rheophytes that are rheophytic in juvenile stages and resemble land plants at maturity. Although their leaf shape is believed to change gradually from narrow-lanceolate juvenile leaves to broadly lanceolate adult leaves, our field observations show that in Saraca declinata and Tristania whitiana, tropical paedorheophytes, have two and three classes of leaf shape, respectively, which change abruptly from one class to the other during the growth.

Key words: Leaf shape, paedorheophyte, shrubby rheophyte.

Van Steenis (1981) は溪流沿い植物 rheophyte をつぎのように定義した。Plant species which are in nature confined to the beds of swift-running streams and rivers and grow there up to flood-level but not beyond the reach of regularly occuring flash floods. 意訳すると、自然状態では急流に限って、しかも定期的に起る増水の冠水面を越えない部 分に生育する種ということになる。筆者の経験からしてこの急流という条件は増水時に急流となるということ であり、普段はおとなしい流れであってもよい。このような特殊な環境（以下溪流帯という、また、ことわり なく陸上植物という場合には溪流帯より上位に生育する陸上植物を指すことにする）に限って生育する渓流沿 い植物が、いろいろな分類群で独立に生じていることはすでによく知られている。その中には草本性のものも あるし、ごく小型の木本から 20 メートルに達する高木まで様々である。

渓流沿い植物が必ずしも外部形態的特徎（の分化）を伴うとは限らないので、中には母種である陸上植物と 区別がつかず、そのために同一のものが陸上から溪流帯まで広く分布しているように見えるものがあるかもし れない。それにもかかわらず多くの渓流沿い植物にはいくつかの共通した形態的特徴が見いだされており、そ れらは渓流環境に適応したものであるとみなされている。手短かに言えば1）発達した根や付着茎のシステム、 2 ）流線型の葉や小葉、3）柔軟な茎や葉柄、4）平滑、全縁な茎や葉、などである。1）は植物体を流され 難くするための適応であり、2）－4）は流水に対する抵抗を減らすための適応であると考えられる。

木本性の渓流沿い植物の場合、これらに加えて分枝、樹形にも一般的な特徴が知られている。川岸に生育 するものでは茎はほほ真横に流れの方向（川の中央）に向って伸び、やや斜上または斜下する。これは光りを 求めて空間の空いている流れの方に成長するためと考えられる。また枝は一般に下流方向に伸びる。これは流 水により強制的にねじ曲げられるためと思われる。もうひとつの特徵は、枝先で節間がつまり、多数の葉が混 みあってつくと同時に盛んに仮軸分枝を繰り返すことである。この結果、上面に葉が集中する平らな樹冠が形 成される。カリマンタンで最も普通に見られる例は川岸に生育するアカネ科の Myrmeconauclea strigosa (Fig. 1)、 川床に生育するAglaia rivularisなどで、樹冠平面はほほ増水時の水面付近に位置しているように見受けられた。 
個々の枝先は流水中で傘状にすはまることにより抵抗を減らしていると言われている。また比較的流速が遅い 水面付近に壊れ易い葉や枝先を集中することによりダメージを少なくするとともに、少しでも早く水面上に出 て光合成を行うのにも適した形態であると考えられる。枝先を水面の上に出して流れを避けるというような適 応を示すものは見つからなかった。また、花の位置や開花状態の花の形態には近縁の陸上種との間で特に差が 認められなかった。

さらに大型の木本では増水時に水流の影響を強く受ける幼期にのみ溪流沿い植物の形態的特徵を示す幼期溪 流沿い植物 paedorheophyteが知られる。このような植物が生じていることは、当然のことながら、環境の選択圧 が生活史の一部に働いた場合にそこに特有な適応が起こり得るということを示している。幼期渓流沿い植物が 陸上性の母種から由来したならば、幼期に発現する渓流型の形質は由来的（apomorphic）なものであり、冠水の 影響を受けなくなった成木の状態では祖先的（plesiopmrphic）な形質を示すと考えられるのて、通常の溪流沿い 植物 のように近縁の祖先種を推定するわずらわしさがなく、適応進化について同一個体内で直接的に比較する ことができる。

幼期渓流沿い植物として最もよく知られてきたのはマレー半島とボルネオ島に分布するフタバガキ属の Dipterocarpus oblongifolius である。1989 年の東カリマンタンでの調査時（9月）はちょうど花時にあたり、 垂れ下がった枝にたくさんの白い花がついているのが見られた。フタバガキ属は典型的な木本性の科であり、 約 80 種あるうちのほとんどが樹高数十メートルに達する直立性の陸上植物であるが、ただ 1 種この

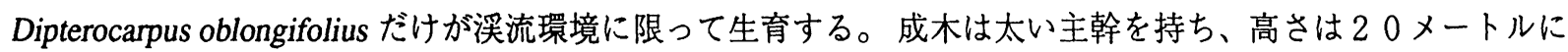
達するが、主幹は常に川岸から流れに向ってほほ水平に伸びすぐに斜上する（Fig. 2）。成木の葉は長楕円形で leaf-index I = 2.5-4と報告されている。これに対し、幼木では茎が細く柔軟でよく分枝し、斜上、ときにはやや垂 れ下がっていた。また、成木にくらべて葉が細く（葉相対長 leaf-index I=8-10)、典型的な溪流沿い植物の形 態的特徽を示していた（Fig. 3）。Dipterocarpus oblongifoliusでは、陸上で栽培しても幼期には細い葉を持つ（I =8-10)ということが確かめられており (Srivastava, 1977 ; van Steenis, 1981)、幼期の特殊な葉型は遺伝的に決って いて渓流条件がなくても自動的に発現することが知られている。Van Steenisは木が成長し水の影響を受け難く なるにつれて次第に幅広い葉を持つようになるとしているがこれは疑わしい。むしろ後で示すTristania whitiana での観察例のように、葉の相対長を決定する遺伝情報が段階的（この場合は 2 段階）に発現し、ある成長段階 で突然幅広い葉を持つようになる可能性が高いと思われる。盛んに分枝する渓流型の幼木からどのようにして 斜上する一本の太い主幹を持つようになるかは詳しく観察されていないが、幹が屈曲する位置に分枝の先端の 名残を思わせるコブがあることからみて、幹は一本の茎ではなく仮軸分枝した茎と枝の複合体であり、主幹の 基部がほほ真横にのびているのは幼期の樹形の名残りと思われる（Fig. 4 参照）。

東カリマンタンでは幼期渓流沿い植物としてこのほかにフトモモ科の Tristania whitianaとマメ科のSaraca daclinata （Fig. 4）が観察された。これらの生育環境はDipterocarpus oblongifoliusとよく似ており、まれに混生す ることもあった。また、幼木、成木の樹型もそれぞれDipterocarpus oblongifoliusによく似ており、岸から流れに 向って斜上する典型的な幼期渓流沿い植物の特徴を示していた。これらの種の葉型の変化をFigs. 5, 6に示す。 Tristania whitianaでは葉型に 3 通りあり、幼期に最も細長く、成木の栄養枝では長さはほとんど変化しないが幅 広くなり、花序の枝につく葉はさらに幅広くなっている。得られたデー夕を見る限り、葉の幅が少しずつ広く なるということはなく、したがって Tristania whitianaでは葉の形を決める遺伝情報が成長段階に応じて 3 段階に 順次発現すると推定される。Van Steenis は渓流沿い植物としてほかに３種のTristania 属植物をあげている。そ のうち 1 種は潅木であり、2 種が高木であるが葉の 2 型性については触れていない。

Van Steenis はSaraca 属植物に言及して、この属は渓流帯（冠水域）を越えた河畔の森林中にも出現するし、 幼期の適応も認められないので渓流沿い植物とは言えないとしている。ビルマからマレーシア地域に広く分布 
するSaraca daclinata については、いろいろな環境に生え、時に川沿いにも見られる（意訳）としている。しかし カリマンタンでは生育環境の点でも形態的にもこの種が幼期渓流沿い植物であることは明らかである。Van Steenisの観察も正しいとすると、同一種のなかに純粋に陸上性の集団と渓流帯の集団がある、つまり条件的な 溪流沿い植物であることになる。純粋に陸上性の集団においても溪流帯の集団で観察されたような葉形の変化 が起るかは興味深い。なぜなら、陸上集団から渓流沿い集団が派生したのであれば葉形変化葉一種の前適応と みなすことができ、また、渓流沿い植物が分化した後、さらにその一部が陸上へ復帰するという第 2 段階の適 応分化が進みつつあると考えることもできるからである。

1989年と1990年に 2 度にわたりボルネオ島（カリマンタン）での溪流沿い植物の調査に参加し、現地調査を 行った。この小論は主にその調查結果とvan Steenis (1981)に基づいてまとめたものである。

引用文献

Steenis, G.G.G.J. van. 1981. Rheophytes of the World. 406pp. Sijthoff \& Noordhoff, Alphen aan den Rijn. Srivastava, P.B.L. 1977. Precocious flowering (paedogenesis) in Dipterocarpaceae. Mal. For. 40: 251 - 253. 

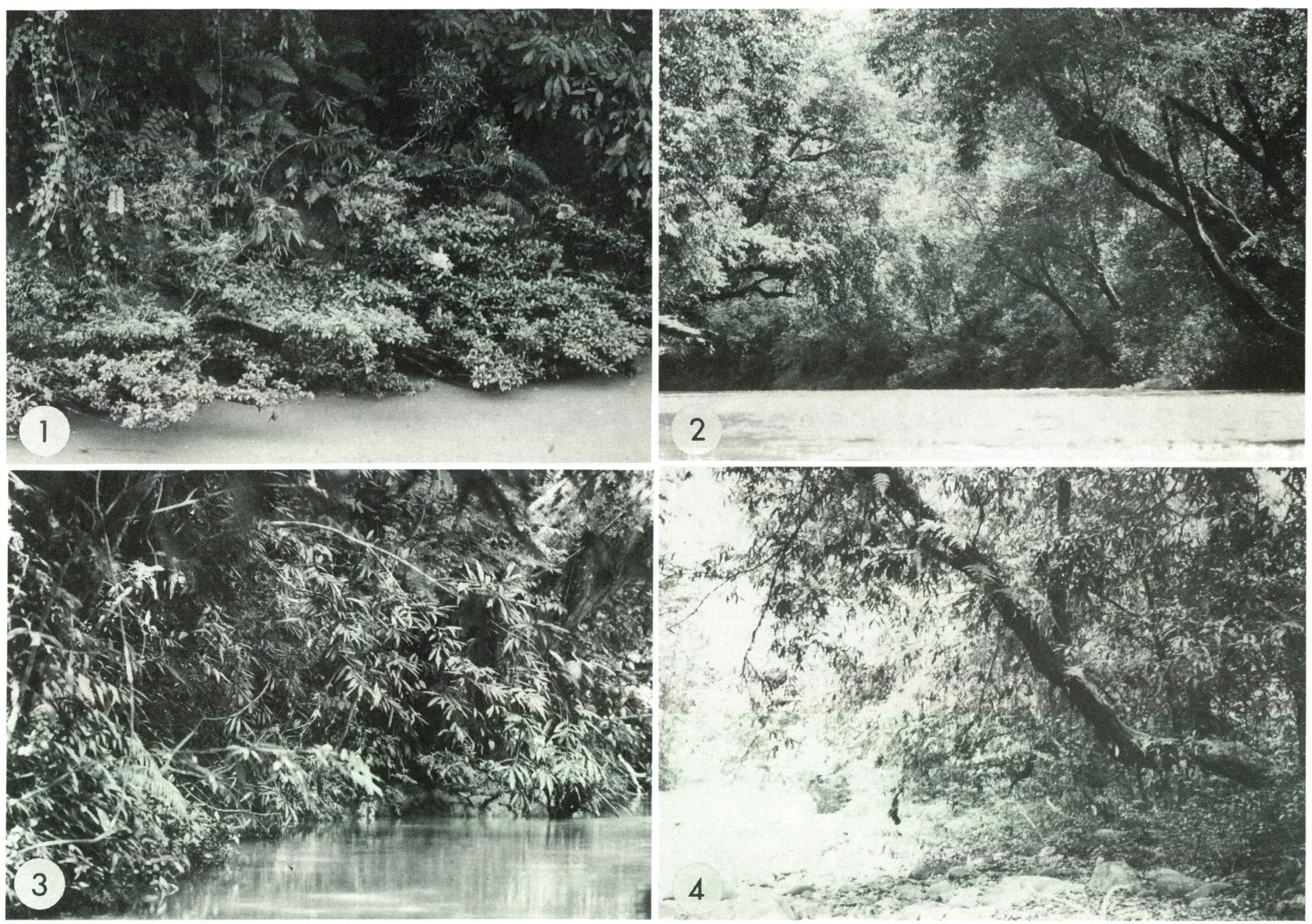

Figs.1-4. Habitat and hab it of theophytes. Fig. 1. Myrmecon au clea strigosa growing on river bank just ab ove water level. Fig.2. Adult plants with obliquely ascending trunks of Dipterocarpus oblongifolius. Fig.3. Ju venile plants of D. oblongifolius. Fig.4. Adult plant of Saraca daclinata. Note that the trunk is the horizontal at the basal portion and obliquely ascending above it. 


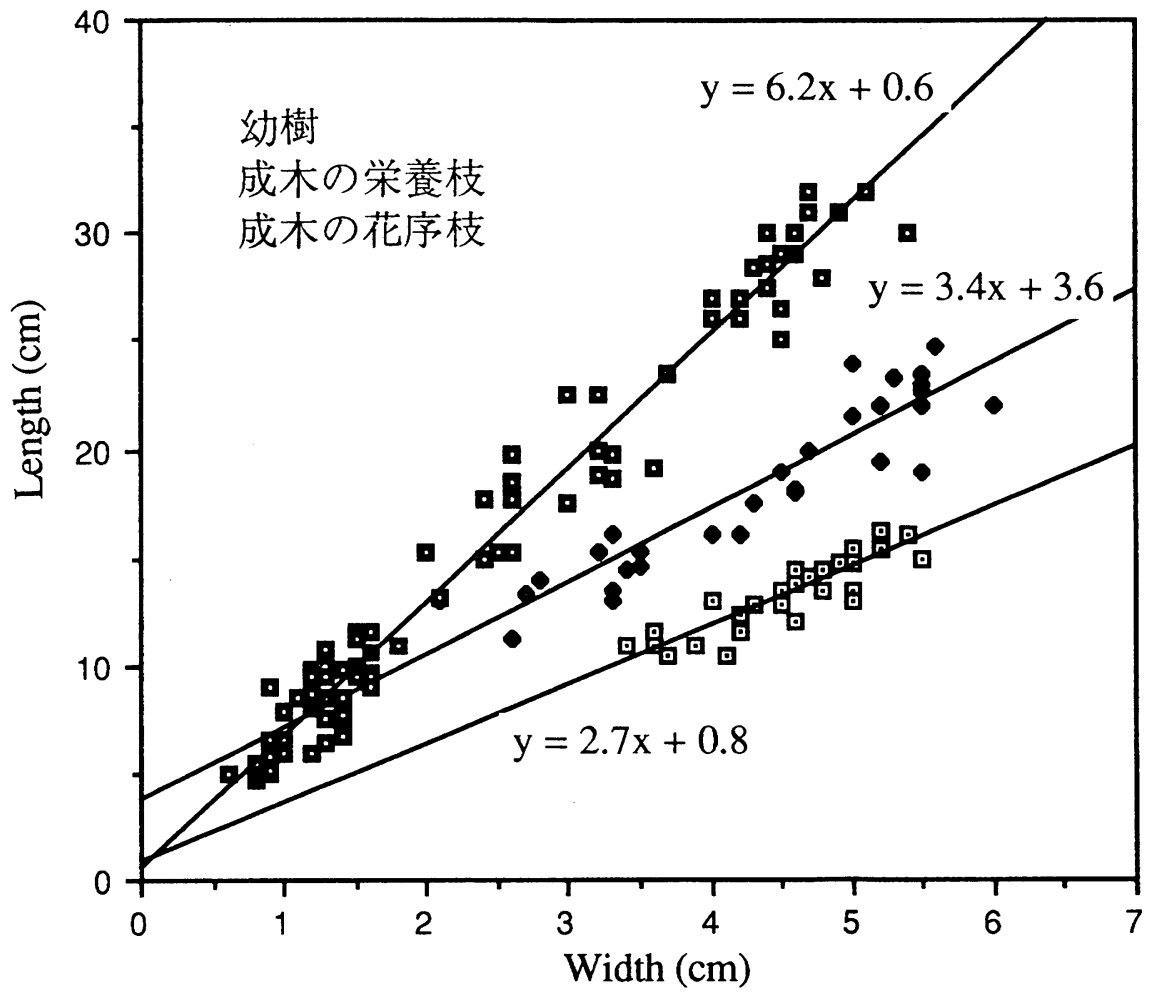

Fig. 5. Leaf shape of Tristania whitiana. a Juvenile plants. - Vegetative shoots of adult plants: - Reproductive shoots of adult plants.

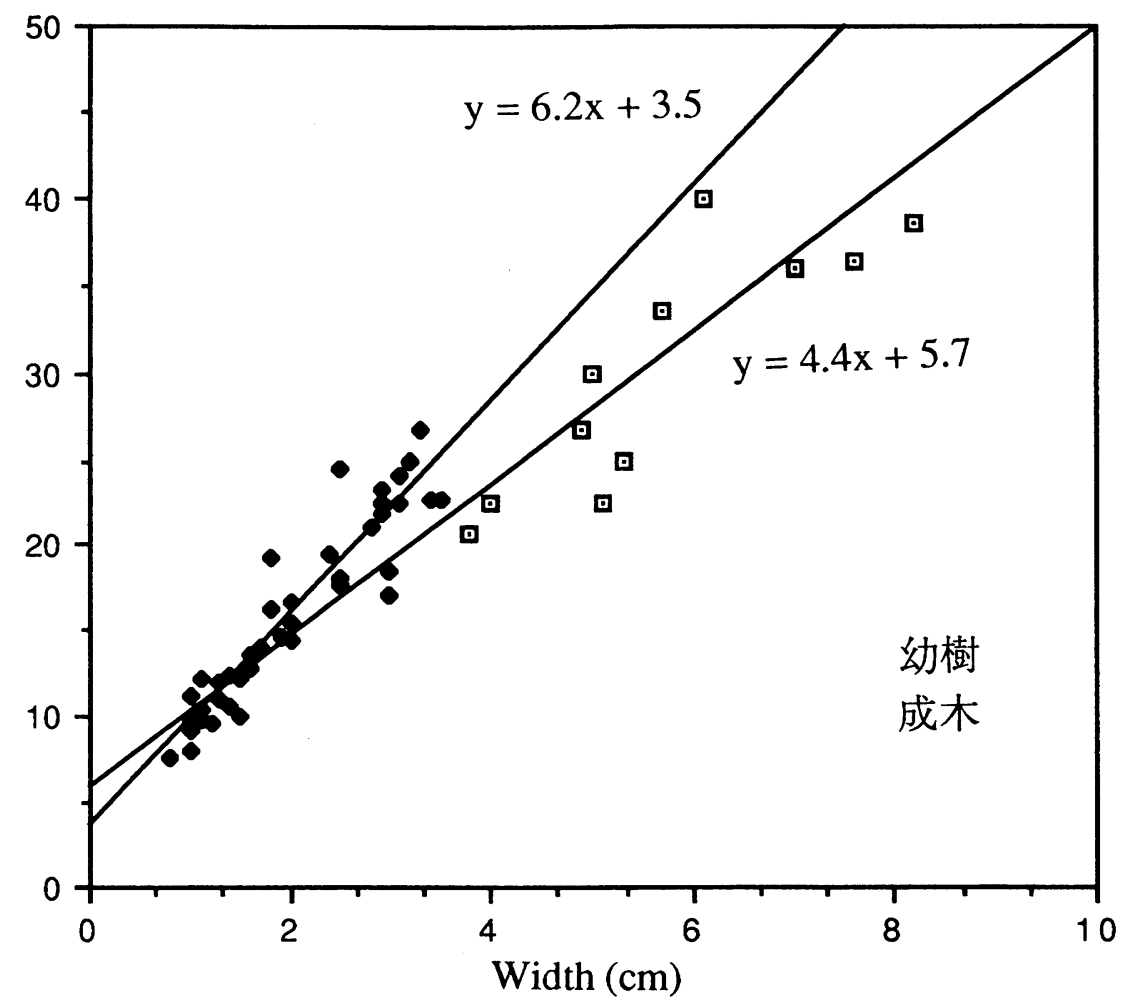

Fig. 6. Leaf shape of Saraca daclinata. $\bullet$ Juvenile plants. - Adult plants. 